\title{
La elite rural y su inversión en la educación formal a fines del siglo XIX: El caso de Pedro C. Molina (1880-1914)
}

\author{
[The Rural Elite and its Investment in Formal Education at the End of the 19th \\ Century: The Case of Pedro C. Molina (1880-1914)] \\ Dahyana Nahir López \\ Universidad Nacional de Río Cuarto \\ licdahyanal@gmail.com
}

\begin{abstract}
Resumen
El presente artículo se centra en el estudio de la trayectoria de vida de Pedro C. Molina (18531920), fundador de la localidad de Almafuerte en la provincia de Córdoba y político de la Unión Cívica Radical (UCR). Perteneció a una familia de estancieros, vinculados a la posesión de una merced de tierras en la zona de Tercero Arriba, cuya prosapia se remonta a los Molina Navarrete. Por lo que la familia Molina contaba con cierto prestigio desde la época colonial. Sin embargo, para fines del siglo XIX estas familias se encontraban en una fase de decadencia en la reputación dentro de la elite cordobesa. Pese a que Molina iba a heredar una fracción de tierra de la Estancia El Salto, su posibilidad de acceso a la educación le permitió forjar su camino dentro del ámbito intelectual y político de Córdoba y proyectarse a nivel nacional como referente dentro de la UCR.
\end{abstract}

Palabras claves: Elite rural - Educación formal Pedro C. Molina.

\begin{abstract}
This article focuses on the study of the trajectory of Pedro C. Molina (1853-1920), founder of the town of Almafuerte in the province of Córdoba and a politician of the Unión Cívica Radical (UCR). He belonged to a family of landowners who possessed a land grant in the area of Tercero Arriba and whose lineage went back to the Molina Navarrete. For that reason, since colonial times, the family had a certain prestige. However, by the end of the nineteenth century, these families were in a phase of decline in reputation within the Cordoba elite. Although Molina was going to inherit a piece of land from the Estancia El Salto, his ability to access to education allowed him to forge his way into the intellectual and political environment of Córdoba and to be projected at the national level as a reference within the UCR.
\end{abstract}

Keywords: Rural Elite - Formal Education - Pedro C. Molina.

Recibido: 10/01/2019

Evaluación: 23/04/2019

Aceptado: 25/07/2019

Anuario de la Escuela de Historia Virtual - Año 10 - N 16 - 2019: pp. 7-24.

ISSN: 1853-7049

http://revistas.unc.edu.ar/index.php/anuariohistoria 


\section{La elite rural y su inversión en la educación formal a fines del siglo XIX: El caso de Pedro C. Molina (1880-1914)}

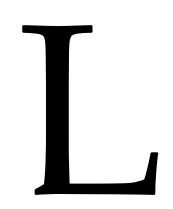

a expansión agraria en la pampa húmeda y el traspaso de las tierras públicas a manos privadas, que se profundizó después de 1880, se insertó dentro del proceso económico impulsado por la demanda de materias primas y alimentos en los países industrializados que llevó a la integración de Argentina en el mundo capitalista. Así, nuestro país se organizó social y políticamente en torno a las actividades agropecuarias. A su vez, se propició las condiciones para la creación de instrumentos jurídicos que aseguraron la propiedad privada de la tierra y que favorecieron el ingreso de capitales y bienes del exterior. Este proceso histórico que caracterizó el final del siglo XIX, cuya derivación fue la formación del Estado moderno, de una economía de mercado y de una sociedad dominada por una elite empresarial, reconoce matices regionales y especificidades locales que enriquecen la visión de conjunto.

En ese contexto de transición, se vuelve significativo explorar el papel que cumplió la educación para la elite rural en ese nuevo entramado económico, especialmente para aquellos sujetos que tenían concentradas sus actividades económicas en espacios que comenzaban a perder significatividad productiva con el traslado del eje al sur y este provincial. Sobre esa consideración, este trabajo se centra en el estudio de la trayectoria de vida de Pedro C. Molina (1853-1920), fundador de la localidad de Almafuerte en la provincia de Córdoba y un destacado dirigente de la Unión Cívica Radical (UCR). ${ }^{1}$ Molina fue hijo del matrimonio de Pedro Nolasco de Molina Maldonado con Doña Petrona Camacho. Una familia de estancieros, vinculados a la posesión de una merced de tierras en la zona del actual departamento de Tercero Arriba, cuya prosapia se remonta a los Molina Navarrete asociados a las primeras expediciones que llegaron a la zona de Córdoba acompañando a Jerónimo Luis de Cabrera. ${ }^{2}$ Esta información hace presumir que la familia Molina contaba con cierto prestigio desde la época colonial. Sin embargo, para fines del siglo XIX e inicios del XX estas familias tradicionales se encontraban en una fase de

\footnotetext{
${ }^{1}$ Este trabajo forma parte del trabajo final de grado "Pedro C. Molina, la política y los negocios. Trayectoria y estrategias de un empresario rural (1880-1914)", dirigida por el Dr. Gabriel Carini y codirigida por la Dra. María Rosa Carbonari, defendida y aprobada en diciembre de 2018.

${ }^{2}$ La merced de tierras fue otorgada a Juan Molina Navarrete por su participación en la expedición de Jerónimo Luis de Cabrera, las mismas abarcaban las pedanías El Salto, Las Peñas y Tegua. Luego, su descendencia fue reclamando sobras de tierras como reza la siguiente fuente: "el Capitán Alonso de Molina Navarrete, vecino morador de [...] cuidad [de Córdoba] y me hizo relación diciendo le hiziese merced de las sobras circunvecinas a la Estancia del Salto que tiene y posee veinte leguas [...]por todas partes, así de una vanda del río, como de la otra; lo que por mí visto mandé se le despachase título en forma, por ser como el susodicho es, hijo y nieto de pobladores y conquistadores [...] por ser persona noble y principal y haber servido a su Magestad en todas las ocasiones qe, se ha ofrecido en los socorros qe, se han hecho en el valle calchaquí, Rioja y Londres y ciudad de Buenos Aires, Río de la Plata, dando escudero y lo demás qe, se ha pedido." AHPC. Año 1913, Juzgado de $2^{\circ}$ civil. Leg. 13 Exp 2, f. 85, 4256.
}

Anuario de la Escuela de Historia Virtual - Año 10 - N 16 - 2019: pp. 7-24. ISSN: 1853-7049 
decadencia en cuanto a la reputación dentro de la elite cordobesa. Pedro C. Molina como descendiente de los primeros colonizadores españoles en la región, iba a heredar una fracción de tierra de la Estancia El Salto, un espacio que perdía significatividad productiva frente al pampeano. ${ }^{3}$ No obstante, su posibilidad de acceso a la educación le permitió forjar su camino dentro del ámbito intelectual y político de Córdoba y proyectarse a nivel nacional como referente dentro de la UCR. ${ }^{4}$ En ese sentido, sostenemos que el acceso a la formación universitaria para los miembros de una elite en declive social se convirtió en un mecanismo para reproducir, no solo su prestigio, sino alcanzar también posiciones políticas y multiplicar su capital económico.

Nos concentraremos en el análisis de la trayectoria de vida ${ }^{5}$ de Molina dentro del período abarcado por los años 1880 a 1914. Este lapso de tiempo incluye la etapa como profesional y político que inicia luego de graduarse de abogado; la influencia de su matrimonio con Ventura Barros y su actividad política, tanto en Córdoba como en Buenos Aires. Su apogeo en el ámbito público lo coloca en el plano nacional como un referente sumamente importante que llega a disputar la conducción del partido de la UCR con Yrigoyen. El ocaso de su vida estuvo marcado por el quiebre con la UCR y la fundación de la Villa de Almafuerte en sus tierras localizadas en la región de El Salto, departamento Tercero Arriba. ${ }^{6}$

Bajo ese marco y teniendo presente las características del problema a investigar se empleó una metodología predominantemente cualitativa, centrada en el empleo de la observación documental, que incluyó la lectura y análisis de diversas fuentes presentes en diferentes reservorios. Entre los documentos consultados se encuentran las actas notariales, las escrituras de compra-venta y las mensuras de las estancias La Merced, Monte Grande, La Ventura y El Salto, las que se conservan en el Archivo de la Dirección General de Catastro de la Provincia de Córdoba (ADGC) y en el Archivo Histórico de la Provincia de Córdoba (AHPC). Mientras que, en el Archivo Histórico del Arzobispado de Córdoba (AHAC) y el Archivo General de la Nación Argentina (AGN), se consultaron las actas de bautismo, de matrimonio y los registros censales de personas de los años 1869 y 1895 . Este conjunto de fuentes, dieron cuenta de la vida económica y social de la familia y sus

\footnotetext{
${ }^{3}$ Los Molina como una familia de estancieros fueron perdiendo posición social dentro de la elite cordobesa, en contraposición del sostenido aumento del patrimonio familiar. En 1840 contaban con una importante propiedad que alcanzaba las 45.454, 34 hectáreas de tierras en el margen norte y sur del río tercero (pedanía El Salto, región del Tercero Arriba) dirigida por Pedro Nolasco Navarrete Molina Vilches. AHPC. Año 1886 Juzgado de $2^{\circ}$ civil. Leg. 13. Exp 6, f. 21.

${ }^{4}$ Ocupó en reiteradas oportunidades la presidencia del Comité Nacional (Vidal, 2014).

${ }^{5}$ Cabe advertir que las trayectorias no necesariamente abarcan la totalidad de la existencia del sujeto, sino que el recorte temporal se construye en función del objeto de estudio teniendo presentes las características anteriormente mencionadas (Longa, 2010). Por lo tanto, la trayectoria de vida de los sujetos está intrínsecamente asociada al tiempo y lugar que enmarca sus experiencias concretas. De esta forma, adquiere centralidad el análisis del contexto histórico social y geográfico en que se desenvuelve la vida de las personas, en particular, de la red de relaciones que construyen (Sepúlveda Valenzuela, 2010, pp. 27-53).

6 Para ampliar sobre otros aspectos de la vida de Pedro C. Molina (López, 2017).
}

Anuario de la Escuela de Historia Virtual - Año 10 - N 16 - 2019: pp. 7-24. ISSN: 1853-7049 
10 | La elite rural y su inversión en la educación formal a fines del siglo XIX...

intercambios con el entorno. En el Archivo de Gobierno de Córdoba (AGC) y en el Archivo de la Legislatura Provincial (ALP) se encuentran decretos e informes sobre obras públicas para la región. Sin embargo, motivado por el carácter fragmentario de las fuentes primarias, apelamos al uso del paradigma indicial propuesto por Carlo Ginzburg (2018), que permite a través de vestigios e indicios poder reconstruir detalles y aspectos del objeto de estudio.

El presente artículo se organiza en tres secciones. El primer apartado aborda las claves historiográficas sobre la elite rural letrada a fines del siglo XIX, enfocado en la influencia de la educación para el ejercicio de una profesión y la actividad empresarial, sumado al aporte de los vínculos sociales que se propiciaban en el ámbito intelectual. Luego, en una segunda sección, se avanza sobre la reconstrucción de la trayectoria familiar de los Molina, centrada en su arraigo colonial y a la nobleza. Además, se detalla la vinculación de La Estancia El Salto y la administración de la familia Molina hasta llegar a fines del siglo XIX con la gestión de Pedro C. Molina. Finalmente, el trabajo concluye con la trayectoria de vida de Don Pedro y la injerencia de la educación en las diversas actividades que este sujeto desarrolla en el período abarcado.

\section{Claves historiográficas sobre la elite rural y su acceso a la educación superior a fines del siglo XIX}

La historiografía sobre los grupos dominantes del último cuarto del siglo XIX y la coyuntura histórica de la inserción de Argentina al mundo capitalista desde una economía con un modelo agroexportador ha sido ampliamente estudiada. Las primeras corrientes de principios del siglo XX enfatizaban la naturaleza agraria de esta elite. Descripta habitualmente como una oligarquía terrateniente, que se apoyó tanto en su dinamismo económico como en su capacidad para controlar el Estado e imponer su autoridad sobre la sociedad (Hora, 2014). Avanzada la segunda mitad del siglo, se continuaba abonando la construcción de una imagen de los terratenientes pampeanos como una clase cuya riqueza residía en el control de grandes extensiones de tierras y en prácticas económicas

especulativas que permitían la reproducción de su capital sin asumir riesgo empresario (Carini, 2018).

En el marco del retorno a la democracia, surgió, sin embargo, una renovación. Jorge Sábato (1991) instaló el concepto de clase dominante como multi-implantada. En su libro La clase dominante en la Argentina moderna, formación y características, este autor usó la categoría histórica de terratenientes para referirse al grupo dominante de la época, cuyo ingreso provenía de la renta de grandes extensiones de tierra de su propiedad. Además, observó que en el interior de este grupo se producía cierta movilidad vertical, reemplazos y sustituciones, lo que manifestó la difusión de pautas de comportamiento que estimulaban a los terratenientes a diversificar sus actividades en distintos sectores económicos. Por esta razón, incorporó como novedad en el comportamiento de este grupo el 
desarrollo de otras actividades económicas como el comercio y las finanzas de forma simultánea a la producción agropecuaria.

En los últimos años del siglo pasado, el campo historiográfico se ha interesado en indagar espacios antes poco atendidos, mediante la incorporación de variables socioculturales y el empleo de nuevas fuentes que renovaron la mirada sobre el pasado de estos actores. Esta nueva línea interpretativa hizo uso de las categorías históricas de elite rural y empresario agrícola. Los recientes trabajos sobre los estancieros del período en Buenos Aires, en ese sentido, han mostrado las falencias de la interpretación sobre los terratenientes -defendida por Sábato- al analizar los comportamientos y patrones de inversión de las familias como los Anchorena y los Senillosa, o los individuos como Jean Estrogamou estudiado por Roy Hora o Ramón Santamarina por Andrea Reguera. Estas nuevas investigaciones llevaron a Roy Hora a concluir que "la elite económica se definió más plenamente como un empresariado rural, y crecientemente concentró sus activos e intereses en este sector" (Hora, 2015, pp. 60, 80-81). La orientación de los recursos hacia esta actividad se constituyó en un dato importante para explicar la rapidez de la modernización experimentada por el sector agrario. En consecuencia, criticó la idea de la inversión en el sector secundario y terciario, manifestando que la tierra siempre fue su principal base económica. Al mismo tiempo, este autor agregó que la elite no fue un grupo cerrado e impermeable, sino que, en el dinamismo de la economía exportadora, se dio la emergencia de un número de nuevas fortunas rurales, muchas de ellas de origen inmigrante. Esta hipótesis discrepa con lo expuesto por Sábato, quien había llamado la atención, por su parte, sobre lo cerrado y las dimensiones reducidas de este grupo.

Otra línea interpretativa proviene del paradigma de la economía de la innovación, puntualmente, desde un enfoque schumpeteriano como el presente en la obra de Carmen Sesto. Esta investigadora critica la visión que centra la racionalidad económica en maximizar beneficios solo a través de las grandes propiedades de tierra, enfocando en el tamaño y la localización de los predios, postergando la introducción de nueva tecnología y sin analizar la calidad o el rendimiento vacuno. La postura de esta autora se ajusta a un recorte espacial propio y se diferencia de las posturas que objeta, ya que se centra en la "vanguardia ganadera" en Buenos Aires. Por ello, sostiene que el incremento de la productividad demandó una infraestructura de alta complejidad para el aprovechamiento más eficiente de las tierras, esto fue, "ampliando la oferta forrajera, contrayendo potreros, cabañas e instalaciones fijas y proveyendo agua permanentemente" (Sesto, 2005, p. 34). Al mismo tiempo, esto demandó la modernización no solo en los sistemas productivos y la genética de la carne, sino también de las técnicas administrativas, la reorganización de la mano de obra y de los actores sociales. La línea de investigación de Hora, Reguera y Sesto comparten un aspecto, puesto que hacen referencia a una elite de negocios con perfil rural e identidad empresarial progresista.

En el marco de las transformaciones económicas y sociales que atraviesa la Argentina moderna, "por primera vez la inversión familiar comienza [a orientarse en] alentar la formación superior" (Bragoni, 2001, p. 344). Este fenómeno se entiende en el contexto 
12 | La elite rural y su inversión en la educación formal a fines del siglo XIX...

que describe Carbonari para el sur cordobés: "en los tiempos modernos el abolengo, aunque significativo, deja de ser una condición necesaria para mantener el prestigio y pasa a ser la profesión la que posibilita el acceso a la riqueza que da influencia y por ende poder político" (Carbonari, 2007, p. 1). Así, a fines del siglo XIX, la propuesta educativa para la elite estaba orientada hacia una formación enciclopédica y dirigida a los estudios profesionales universitarios o a la actividad política (Puiggros, 1996, p. 77). A los hombres les estaba permitido la formación profesional y la actuación en la dimensión pública como en la política, los negocios y el mundo de la cultura. Por su parte, a las mujeres les estaba reservado el ámbito doméstico, en el que cumplían los roles de madre, esposa y anfitriona (Losada, 2012). Además, en lo que respecta a las pautas de crianza de los niños de elite, el propósito estaba orientado a inculcar la obediencia fundada en el reconocimiento de la autoridad de los padres y el respeto a la familia. Losada expresa la necesidad de "tener en cuenta que la familia no se restringía a quienes vivían bajo el mismo techo, sino que se la entendía de un modo más elástico, puesto que abarcaba el universo más amplio del parentesco, que incluía a la rama materna, a partir de la cual muchas familias de la clase alta argentina podían acreditar su vínculo con los círculos tempranos o tradicionales del país" (Losada, 2012, p. 28). Al mismo tiempo, según este autor, era en los círculos de sociabilidad donde esta elite de fines de siglo se relacionaba. Específicamente, Losada hace referencia a los lugares de sociabilidad en Buenos Aires, como el Club del Progreso, el Jockey Club o el Círculo de Armas. ${ }^{7}$ Estos círculos eran:

“(...) espacios privados de sociabilidad a través de los que los miembros de un determinado círculo social se reconocen y participan de usos y costumbres comunes. [A la vez, que] constituye[ron] también plataformas de exteriorización social pues las prácticas y conductas que buscan arraigar en sus socios aspiran a subrayar su posición encumbrada frente al conjunto de la sociedad" (Losada, 2006, pp. 547-548).

Para los historiadores que buscan reconstruir las formas de acceso a la producción agraria y el desarrollo de las empresas agrícolas, la familia se presenta, entonces, como un ámbito a analizar debido a las estrategias ligadas a la lógica de comportamiento económico que se despliega en la circulación de la tierra en el ámbito restringido de las relaciones familiares. Esa lógica comprendía estrategias y prácticas tendientes a conservar el patrimonio familiar y reproducir la riqueza material heredada, las que, al mismo tiempo, estaban orientadas a asegurar el prestigio social dentro del grupo de elite (Bragoni, 2001, p. 352). Por lo tanto, el abordaje sobre las familias se enfoca en las relaciones matrimoniales, las prácticas sucesorias y la protección del patrimonio, por ende, se estudia el cuadro de vínculos sociales, económicos y políticos al interior del grupo familiar. En esta línea, Bragoni destaca tanto la importancia de las estrategias individuales hege-

\footnotetext{
${ }^{7}$ El Club del Progreso se caracterizó por ser el club de caballeros más antiguo de Sudamérica. Participaron de este club dos amigos de Pedro C. Molina, Leandro Alem y Aristóbulo del Valle.
} 
monizadas por referentes masculinos en el juego empresarial, como así también, de reconocer el valor en la concertación de matrimonios estratégicos, que se vuelven decisivos a la hora de resolver la herencia y la sucesión debido a que el sistema de reparto no anulaba el acceso de las mujeres a la propiedad inmueble (Bragoni, 2001, p. 363). Por lo tanto, en los próximos apartados nos ocuparemos de la trayectoria familiar de los Molina para luego continuar con la vida de Pedro C., su acceso a la educación y la injerencia de la misma en su actividad profesional, política y social.

\section{La historia de la familia Molina en la región de El Salto}

La familia Molina fue heredera de tierras al sur de la provincia de Córdoba, en la región de El Salto, como así también, sus dominios se extendieron por las pedanías de Las Peñas y Tegua (Carbonari y Baggini, 2004). El linaje de los Molina Navarrete desciende de Juan Molina Navarrete, un español que formó parte de la expedición colonizadora. Por acompañar a Jerónimo Luis de Cabrera, no solo recibió tierras, sino que también ocupó diversas funciones en el cabildo de la nueva ciudad cordobesa (Mansilla, 1982, p. 18). Desde estos comienzos, la historia de la familia Molina y la región de El Salto se fueron imbricando hasta llegar a los días de Pedro Nolasco Molina, padre de Pedro C. Molina. Pedro Nolasco fue hijo de Juan Esteban Molina Vilchez y Antonia Maldonado, se casó con Petrona Camacho, natural de Tucumán e hija de Marcelino y Leonarda Brizuela. ${ }^{8}$ Dicha unión refleja lo que algunos autores han observado sobre una inmigración interna desde la provincia de Tucumán hacia el territorio cordobés, que promovió vínculos políticos y familiares (Nicola Dapelo, 2015, pp. 113-118). De este enlace proceden: Pedro Carlos Molina, Ercila Molina, Etelvina Molina, Abraham Molina, Isabel Molina, Judit Molina $^{9}$ y Mercedes Molina. Pedro C. se casó en dos oportunidades como puede observarse en el cuadro 1. Su primera experiencia matrimonial fue con Ventura Barros Matheu, una mujer de nacionalidad chilena viuda de un hacendado integrante de la elite porteña llamado Felix Urioste. Con quién había tenido cinco hijos: Victoria Urioste, Ramona Urioste, Félix Uriote, Leocaria Urioste y José Urioste. ${ }^{10}$ Otro dato interesante sobre Ventura fue que, por parte de la familia de su madre, era Matheu, un apellido en Buenos Aires conocido en los acontecimientos de la Revolución de Mayo. Por lo tanto, al igual que Pedro C. poseía una raigambre colonial. Al mismo tiempo, este enlace ejemplifica lo que acontece con los vínculos matrimoniales de esta época. Las relaciones entre las familias porteñas con las de las provincias del Interior del país se afianzan hacia

\footnotetext{
${ }^{8}$ AGN, Censo Nacional de Población, año 1869.

${ }_{9}^{9}$ Judit Molina, viuda de Félix Urioste (hijo de Ventura Barros Matheu y Félix Urioste), en segundas nupcias se casó con Agustín Sanmillán, hijo de Ygnacia Fresnadillo y Agustín Sanmillán, exministro General de Gobierno de Córdoba durante la gobernación de Alejo del Carmen Guzmán (1852-1855). El esposo de Judit fue, además, un exponente político dentro de la UCR, participó junto a sus cuñados, Pedro y Abraham Molina, de la asamblea que resolvió la organización del Comité General Directivo en 1890.

${ }^{10}$ AGN, Censo Nacional de Población, año 1869.
}

Anuario de la Escuela de Historia Virtual - Año 10 - No 16 - 2019: pp. 7-24. ISSN: 1853-7049 
la década de 1880 al compás de la integración económica y política de Argentina (Losada, 2012).

\section{Cuadro 1. Descendientes de Pedro Nolasco Molina Maldonado}

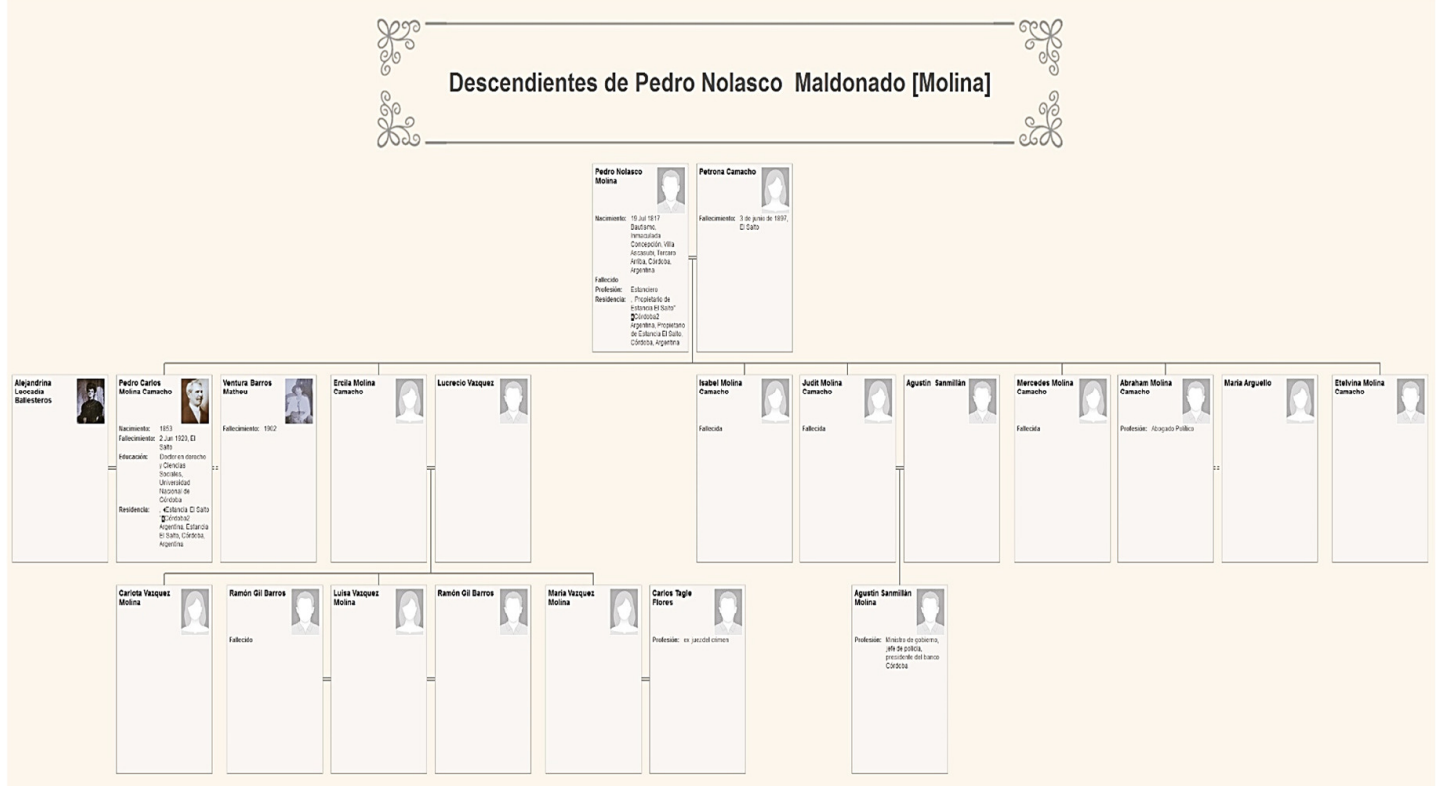

Fuente: Elaboración propia en base a actas de bautismo, matrimonio y otras fuentes complementarias. Archivo Histórico del Arzobispado de Córdoba.

Ventura formaba parte del grupo de damas de la elite bonaerense al estar vinculada a la familia de hacendados de la región central de la provincia, que también integraban las comisiones directivas de la Sociedad Rural Argentina, los Urioste (Newton, 1972). Una vez en Córdoba, como esposa de Pedro, desarrolló diferentes actividades entre las que se destacó la llevada adelante en compañía de su hija Ramona Urioste y las hermanas de Molina, Judith Molina de Urioste y Etelvina Molina, junto a otras mujeres pertenecientes a los sectores sociales más altos de Córdoba, donde obsequian una corona de flores al presidente de la Unión Cívica, Juan M. Garro, en 1890 (Brouwer de Koning, Dallaglio y Errasti, 2004, pp. 8-9). Dicho episodio no fue menor, dado que la política no era, por entonces, uno de los roles socialmente asignados a las mujeres, que tenían toda su tarea en el ámbito doméstico, como asegura Losada (2012). Sin embargo, investigaciones más recientes ponen en discusión tal afirmación. Autores como Paz Trueba (2008; 2009) y Quinteros (2017) observaron que las mujeres de esta elite, por su condición social de ser esposas, hijas y hermanas de los notables locales, sumado a su perfil de educadoras, poseían un prestigio doble que les permitió traspasar las fronteras de su hogar e instalarse en el espacio público por medio de la educación y la beneficencia. Al mismo tiempo, esta línea reconstruyó el acceso de las mujeres a los estudios 
universitarios en Latinoamérica. Palermo (2006, p. 402) observó que en Argentina, desde la década de 1880, la reivindicación del derecho a la educación de la mujer fue de la mano de la exigencia de su presencia en el espacio público, tanto en actos, recepciones, banquetes oficiales, como también a través de su expresión en la literatura, el periodismo y la docencia.

Pedro C. Molina, luego del fallecimiento de Ventura en 1902, contrajo matrimonio con Alejandrina Leocadia Ballesteros Barros, sobrina de su difunta esposa, quién vivía con sus tíos en la Estancia de El Salto desde hacía varios años, tal como hace constar el censo nacional de 1895. ${ }^{11}$ Pese a su segunda nupcias, tampoco tuvo hijos con Leocadia, sino que sus bienes fueron heredados por los hijos de Ventura con su primer esposo.

En suma, la familia Molina hunde sus raíces en la época colonial como poseedora estable de la merced de tierras en la región de El Salto. Las fuentes manifiestan como el patrimonio no solo se conserva dentro de la familia, sino que se amplía en reiteradas oportunidades como, por ejemplo, en 1662 y en $1840 .{ }^{12}$ La Estancia El Salto fue administrada por los varones de la familia, tal como continuó ocurriendo a lo largo del tiempo hasta llegar a la situación en la que Pedro Nolasco deposita en manos de su hijo mayor la gestión de la propiedad (ver Cuadro 1. Descendientes de Pedro Nolasco Molina Maldonado). Los vínculos matrimoniales que se estrecharon en el círculo más íntimo de Pedro C. favorecieron la consolidación de vínculos políticos y sociales dentro del círculo de sociabilidad que frecuentaba este sujeto, tales como diferentes comités de la UCR, el Club social o el Ateneo de Córdoba. ${ }^{13}$ Las relaciones matrimoniales y las prácticas sucesorias dentro de la familia Molina fortalecieron la protección del patrimonio, inclusive en los casos mencionados de Pedro y Abraham, donde heredaron sus hijastros. Al mismo tiempo, la habilidad empresarial de Pedro C. le permitió administrar la propiedad común con sus hermanos, como así también implementar estrategias de negocios para aumentar el capital e incorporar nuevas estancias a su patrimonio personal.

\section{La trayectoria de vida de un abogado, político y empresario: Pedro C. Molina}

El linaje Molina tuvo numerosos exponentes de alto rango civil o militar, no obstante, se caracterizó por su impronta de estancieros abocados al trabajo en sus tierras desde la época colonial (Mansilla, 1982). Sin embargo, como ya se mencionó, a fines del siglo XIX para conservar el prestigio social, la educación superior y la profesión se convirtieron en

\footnotetext{
${ }^{11}$ Alejandrina Leocadia Ballesteros Barros fue hija de José Ballesteros y María Ignacia Barros. Registros parroquiales, 1737-1977, Alejandrina Leocadia Ballesteros, 19 febrero, Nuestra Señora de La Merced, Ciudad de Buenos Aires, Capital Federal. AGN, Censo Nacional de Población, año 1895.

12 AHPC. Año 1886 Juzgado de $2^{\circ}$ civil. Leg. 13. Exp. 6, f. 21

${ }^{13}$ El Ateneo de Córdoba (1894-1913) nucleó a un heterogéneo conjunto masculino de miembros de la elite letrada local, dominado por los doctores en derecho. El objetivo principal de la asociación, definido como "el Cultivo de las Ciencias las Bellas Letras y las Bellas Artes", le abría un vasto campo de actividades: conferencias sobre los más diversos temas, exposiciones y concursos de pintura, veladas literarias, audiciones musicales, diversos homenajes e intervenciones públicas y publicaciones (López, 2009, p. 108).
}

Anuario de la Escuela de Historia Virtual - Año 10 - N 16 - 2019: pp. 7-24. ISSN: 1853-7049 
16 | La elite rural y su inversión en la educación formal a fines del siglo XIX...

un camino para incrementar la fortuna heredada por el abolengo colonial en el sur cordobés (Bragoni, 2001; Carbonari, 2007). Pedro C. cursó el secundario como pupilo en el Colegio Monserrat en la ciudad de Córdoba. Esa institución se había convertido en un ambiente de intercambio de pensamientos políticos entre los alumnos y actuaba como un espacio de sociabilidad en las edades tempranas. Entre los compañeros de estudio de Pedro C. se destacó Guillermo Correa, el hijo del entonces gobernador de Catamarca. ${ }^{14}$ La amistad entre ambos trascendió el secundario y se prolongó durante la carrera de grado.

Los datos arrojados por los censos de 1869 y 1895 constatan que los hermanos Molina fueron los únicos que declararon una profesión diferente de la de estanciero, agricultor o hacendado, como era común en su familia. En consecuencia, ambos se constituyeron en los primeros abogados de su familia que ejercieron en diferentes casos civiles desde su propio despacho de abogados localizado en la capital cordobesa. ${ }^{15}$ Mollis (2016, p. 229) reconoce que era costumbre en este período que los abogados egresados de las universidades estuvieran ligados con la propiedad agraria. Al mismo tiempo, a través de la prensa, se amplió la expresión de las elites, como escritores y poetas. En tal sentido, Pedro C. no solo se destacó como poeta y periodista, sino también se preocupó por la economía, influido por la escuela inglesa de libre cambio (Mansilla, 1982, p. 135). En la participación política, Vicente C. Gallo adjudicó al doctor Molina, y a otros estudiantes, la creación en Córdoba de un movimiento llamado "Moralcracia", el cual consistía, básicamente, en pregonar la práctica moral en la actividad política.

A partir de su enlace con Ventura, Pedro C. afianzó su camino como empresario rural e inició un periodo de expansión territorial de su patrimonio personal mediante la incorporación de lotes ubicados en las pedanías El Salto y Los Cóndores. Al mismo tiempo, con su hermano adquirió los derechos sobre la herencia de la estancia El Salto de sus primos. ${ }^{16}$ La tabla 1 muestra el patrimonio rural de Pedro C. Molina como único propietario, exceptuando las tierras que compró conjuntamente con Abraham y las propiedades urbanas como el despacho de abogados o la oficina de redacción del diario La Libertad en la capital cordobesa de Pedro C. y su hermano (ver Tabla 1. Evolución histórica del Patrimonio territorial de Pedro C. Molina. 1885-1916). ${ }^{17}$

\footnotetext{
${ }^{14}$ Fue hijo del gobernador Ramón Rosa Correa y de Neófita Augier y Correa. Estudió en la Universidad Nacional de Córdoba, donde se doctoró en jurisprudencia en el año 1881.

${ }^{15}$ Como consta en el juzgado de primera, segunda y cuarta nominación, por ejemplo: AHPC, juzgado de $4^{\circ}$ nominación civil Capital (1830-1926), Año 1915, leg. 12, Exp. 10.

${ }^{16}$ En 1890 adquirieron en una venta privada las acciones y los derechos a la herencia sobre la Estancia El Salto a Nicanor Quenón, hijo de Gumersinda Molina de Quenón. AHPC, Juzgado de $2^{\circ}$ civil. Año 1913. Leg. 13. Exp. 2 f. 6 y 7. Pedro C. Molina y otros. Aprob. De Inventarios.

${ }_{17}$ Molina compró el diario La Libertad a David Linares y Sixto Arias Moreno en octubre de 1890 y fue su dueño hasta 1915 cuando el mismo dejó de funcionar. Durante su existencia, el periódico transitó varios cambios de dirección y rotación de individuos. Pedro C. se ausentó o disminuyó su presencia en la redacción durante algunos lapsos, particularmente en los que se avocó a la gestión de sus propiedades en El Salto. Pero aun así el editorial fue constante en relación a tres actitudes: el apoyo al radicalismo, su animadversión con el roquismo y la propagación de un programa liberal político y económico ortodoxo. Cfr. Fernández Seffino, 2017, pp. 4-5.
}

Anuario de la Escuela de Historia Virtual - Año 10 - N 16 - 2019: pp. 7-24. ISSN: 1853-7049 


\section{Tabla 1. Evolución histórica del Patrimonio territorial de Pedro C. Molina (1885-1916)}

\begin{tabular}{|l|l|l|l|}
\hline Fecha & Ubicación & Paraje & Extensión \\
\hline 1885 & $\begin{array}{l}\text { Pedanía El Salto, } \\
\text { dpto. Tercero } \\
\text { Arriba }\end{array}$ & La Merced & 30.655 ha. \\
\hline 1887 & $\begin{array}{l}\text { Departamento Ter- } \\
\text { cero Arriba }\end{array}$ & Monte grande & $2.112,36$ ha. \\
\hline $\begin{array}{l}\text { Sin dato preciso, } \\
\text { conformación de la } \\
\text { Estancia anterior a } \\
1901 .{ }^{18}\end{array}$ & $\begin{array}{l}\text { Pedanía El Salto, } \\
\text { dpto. Tercero } \\
\text { Arriba }\end{array}$ & $\begin{array}{l}\text { Estancia La Ven- } \\
\text { tura }\end{array}$ & $1.883,41$ ha. \\
\hline 1916 & $\begin{array}{l}\text { Pedanía Los Cón- } \\
\text { dores, dpto. Ca- } \\
\text { lamuchita }\end{array}$ & La Aguada & 3,75 ha. \\
\hline
\end{tabular}

Fuente: elaboración propia en base a fuentes catastrales. Archivo de la Dirección General de Catastro de la Provincia de Córdoba (ADGC).

La tabla permite observar que la mayor concentración de tierras estaba localizada en el departamento Tercero Arriba, en las cercanías de la estancia El Salto. Este aumento se desarrolló entre mediados de 1880 y fines del siglo XIX -con la excepción de La Aguada en la pedanía Los Cóndores en 1916- período que corresponde con el tiempo en el que estuvo casado con Ventura y su participación política desde Córdoba. Durante esta etapa, el patrimonio personal de Molina llegó a constar de 34.650,77 ha.

Simultáneamente con este proceso adquisitivo, Pedro C. demostró una constante preocupación por mensurar judicialmente los límites alambrados de las tierras que administraba. Este interés se comprende a la luz del proceso que transitaba nuestro país, la formación del mercado de tierras con la incorporación de territorio para la producción, la sustitución de la cría a campo abierto por la producción de ganado de raza en las propiedades alambradas y la inserción en el mundo capitalista bajo el modelo agroexportador. Lo que refleja dos realidades, por un lado, la expansión de la frontera sobre el territorio indígena y la formación de grandes propiedades bajo el dominio de la clase dominante (Tognetti, 2014, pp. 10-11). Por otro lado, los datos de la tabla sobre la concentración patrimonial de Molina manifiestan el otro extremo, lo que revela la situación particular de la región y muestra los límites del acceso a nuevas tierras exclusivamente por compra o herencia. Esta situación contrasta con el panorama al sur

\footnotetext{
${ }^{18}$ La operación inmobiliaria sobre la estancia La Ventura solo se conoce que los campos "fueron de Doña Engracia C de Cabral y del fisco (hoy de la Estancia La Ventura)". AHPC, Juzgado de $2^{\circ}$ civil. Año 1913. Leg. 13. Exp. 2 f.5. Pedro C. Molina y otros. Aprob. De Inventarios.
}

Anuario de la Escuela de Historia Virtual - Año 10 - N 16 - 2019: pp. 7-24. ISSN: 1853-7049 
18 | La elite rural y su inversión en la educación formal a fines del siglo XIX...

del río Quinto en las últimas dos décadas del siglo XIX y el traslado del eje económico de la provincia hacia el sur y el este (Arcondo, 1970, pp. 12, 15). En este contexto, clausurado el camino de la expansión territorial, la principal novedad fue invertir en la mejora técnica con el fin de incrementar la rentabilidad (Hora, 2012). Las estancias El Salto y La Ventura bajo la gestión empresarial de Pedro C. fueron incorporando elementos como ladrillos para la edificación del casco, la construcción de canales y acequias para el riego de los campos, la diversificación de la producción con la siembra de alfalfares y viñas. Al mismo tiempo, la instalación del alambrado aseguró los derechos de propiedad y estimuló la ganadería puesto que redujo el número de trabajadores, eliminó el sistema de cría a campo abierto con mezcla de ganado de distinta calidad y propietarios, al tiempo que mejoró también el aprovechamiento del suelo.

La necesidad administrativa de los bienes e intereses de Ventura en Buenos Aires tras su fallecimiento, sumado al llamado de la reorganización de la UCR en 1903, motivaron que Pedro C. se trasladara a la Capital Federal. ${ }^{19}$ Meses después, se consagró como presidente del comité nacional de ese partido. ${ }^{20}$ Bajo su dirección, presentó un manifiesto donde se ratificaba el antiacuerdismo y se declaraba la abstención frente a las próximas elecciones.

En este periodo de su vida, marcado por el apogeo político, delegó en su hermano Abraham la administración de las propiedades rurales. ${ }^{21}$ Esto sugiere que, a lo largo de su vida, Pedro $C$. fue creando una red de vínculos en torno a su actividad económica y política integrada por sus hermanos y otros familiares, tales como su cuñado Agustín Sanmillán (esposo de Judit Molina), que constituyeron su círculo de máxima confianza. Esto concuerda con la conclusión de Bragoni cuando expresa que la historia de las familias revela el papel de los vínculos personales en la organización de los negocios y en la política (Bragoni, 2004). A su vez, también refleja que los lazos de parentesco fueron un elemento que caracterizó la formación del poder de los dirigentes de fines del siglo XIX. Por lo que, entonces, "pertenecer a una buena familia [fue] un atributo que sumaba a la hora de actuar en política antes de la apertura democrática" (Ferrari, 2008).

Sin embargo, su presidencia finalizó prematuramente a raíz del fracaso de la revolución de 1905.22 Tras este episodio, "se asiló en Montevideo, [...] asumiendo la responsabilidad que le cabía en la misma, tal como lo declaró en las cartas dirigidas al presidente

\footnotetext{
19 Yrigoyen recuerda en su segunda carta a Molina en 1909 que Pedro: “Volvió usted a la Unión Cívica Radical a invitación nuestra". En: "Ley 12839. Documentos de Hipólito Yrigoyen. Apostolado Cívico - Obra de Gobierno Defensa ante la Corte", Talleres Gráficos de la Dirección General de Institutos Penales, Buenos Aires, 1949.

${ }^{20}$ En 1904 firma el manifiesto del comité de la UCR como presidente (Mansilla, 1982, p. 53).

${ }^{21}$ En las fuentes de esta etapa se observa la ausencia de Molina en contraposición a la intensa actividad adquisitiva de tierras de su hermano. AHPC, Juzgado de $2^{\circ}$ civil. Año 1913. Leg. 13. Exp. 2, ff. 5, 6, 7 y 23. Pedro C. Molina y Mercedes. Aprob. De Inventarios.

22 En febrero de 1905 estalla una revolución impulsada por Yrigoyen, lo llamativo fue que Molina, como presidente del Comité Nacional, no estaba de acuerdo con esta estrategia. En esta ocasión tuvo como epicentros a Mendoza, Bahía Blanca, Rosario y Córdoba. Fue en esta última, donde el vicepresidente de la República José Figueroa Alcorta fue sorprendido y hecho prisionero. Además, allí los revolucionarios nombran gobernador al coronel Daniel Fernández y como ministros a los doctores Abraham Molina y Aníbal
} 
Quintana" (Vidal, 2014, p. 186). Dichas epístolas fueron un fiel reflejo de su pensamiento crítico sobre el sistema político argentino y su defensa del liberalismo económico (Mansilla, 1982, pp. 57-62). Pedro C. tuvo que solventar los gastos de toda o buena parte de esta revolución. La suma aproximada fue de unos cien mil pesos, según Velasco (Mansilla, 1982, p. 142). Con el objetivo de recomponer su situación, Molina se entregó de lleno a la gestión rural durante casi dos años, luego de volver de Montevideo. ${ }^{23}$

La serie de acontecimientos, luego del episodio de 1905, marcó el inicio del ocaso político de Pedro C. El Dr. Yrigoyen, en una de sus cartas, refiere al respecto que: "el Partido lo elevó a la cima y desde allí es que usted se precipitó, por más que se hizo todo lo que era dable para contener y evitar su caída [...] Vano afán el del distinguido compatriota, de responsabilizar de sus desdichas a determinadas personas, que en nada han contribuido a la pérdida de su fe o al debilitamiento de sus energías». ${ }^{24}$ La persistencia por debatir la esencia del radicalismo lo llevó a polemizar durante 1909 con Yrigoyen y, finalmente, implicó su alejamiento de esa fuerza política.

No obstante, gracias a su activa participación política, Molina trabó relaciones con distinguidas personalidades dentro del espectro cultural, del ámbito intelectual y político de la época. Estos contactos se vieron afectados notablemente por los cambios de residencia, que alternó entre Córdoba, Buenos Aires y El Salto, por lo que fueron de duración variable. Un ejemplo de ello fue Bonifacio Palacios, conocido también por el seudónimo de Almafuerte, fue un maestro y poeta argentino. Existe un mito de que, debido a su amistad y gran admiración, Pedro C. bautizó la Villa que nació en sus tierras como Almafuerte; por el mismo motivo, también se encuentra el indicio que asegura la relación entre el plano de La Plata ideado por Dardo Rocha y el diagramado para la localidad, de iguales características.

Los vínculos amistosos que logró entablar Molina, en su mayoría, tuvieron lugar en su círculo de sociabilidad: los comités y clubes que la UCR había implementado para atraer a la ciudadanía que hasta ese momento había mostrado poco interés en involucrarse políticamente con los acontecimientos que el país estaba viviendo a fines del siglo XIX. Estableció amistades con Leandro Alem, Bernardo de Irigoyen, Aristóbulo del Valle, Pedro Goyena, Wenceslao Escalante, Vicente C. Gallo y Juan M. Albarenque. ${ }^{25}$

Pérez del Viso. La revolución fue primero vencida en Mendoza y, luego, en Córdoba, donde los ejércitos nacionales al mando del general Wintter repusieron al gobernador José V. de Olmos. Este hecho motivó que Pedro C. se exiliara en Montevideo (Persello, 2011).

${ }^{23}$ Relata Yrigoyen que: “Después del retorno a la Patria, de los jefes y oficiales emigrados, [...] [se] resolvió encomendar a la mesa directiva la reorganización -del Partido en toda la República, y usted, en vez de ponerse al frente de esa labor, como presidente [...] se alejó a su estancia, donde permaneció en silencio cercade dos años" Carta de Yrigoyen a Pedro C. Molina, noviembre de 1909. En: “Ley 12839..., op. cit.

${ }^{24}$ Carta de Yrigoyen a Pedro C. Molina. Buenos Aires, noviembre de 1909. En: "Ley 12839..., ibid.

${ }^{25}$ Leandro Alem fue abogado, político, estadista y masón argentino. En 1890 fue uno de los fundadores de la Unión Cívica y jefe político de la fallida Revolución del Parque contra el régimen fraudulento del PAN. $\mathrm{Al}$ año siguiente, lideró el sector de la Unión Cívica que fundó la Unión Cívica Radical. En 1893 lideró una segunda insurrección armada, que volvió a ser derrotada. En las elecciones legislativas de 1895 fue elegido diputado nacional, sin embargo, al año siguiente, se suicidó. Bernardo de Irigoyen fue un abogado, diplomático y político argentino. Dos veces ministro de relaciones exteriores, en 1874 y 1882 y una vez ministro 
20 | La elite rural y su inversión en la educación formal a fines del siglo XIX...

La relación entre Molina y Alem se formaría desde el origen mismo de la Unión Cívica. ${ }^{26}$ Con el tiempo, se forjaría una empatía desde el punto de vista ideológico, debido a que ambos se definieron públicamente como defensores del antiacuerdismo. También el vínculo con Aristóbulo del Valle se construyó desde del mismo mitin del Frontón. Sin embargo, luego de que del Valle impulsará una postura moderada de negociación, se produjo el distanciamiento con Alem y Pedro C. Después, Aristóbulo comenzó a ocupar posiciones dentro de los gobiernos oficiales. Una situación similar ocurrió con la amistad que estrecharon Pedro C. y Vicente Gallo. Este último era tucumano, y de profesión abogado, integró la Unión Cívica Radical desde su inicio formando parte del mismo grupo de jóvenes del que formaba parte Molina, a mediados de la década de 1890. Además, como Pedro C., Gallo fue elegido diputado nacional en 1912.

En cambio, con Juan M. Albarenque la relación se entabló después del regreso del exilio. Cuando la reorganización del partido tuvo a Molina junto a Yrigoyen como presidentes honorarios, mientras que, Albarenque integraba el equipo como vocal del nuevo comité, así forjarían su amistad en el marco de la política. Don Juan describió la influencia del doctor Molina como la de un respetado y reconocido referente nacional, y expresó lo siguiente: “él [Pedro C.] dirigió las multitudes y marcó facetas a los gobernantes desde el rincón modesto de su hogar [El Salto o La Ventura], a donde iban a buscar orientaciones en los momentos de dudas; él tuvo su cátedra, la prensa formada por él" (Mansilla, 1982, p. 137). Además, describe a Molina como "Tribuno y periodista, hombre de ciencia y literato, soñador y labriego [...] fue un propulsor del progreso material y moral de su pueblo". El Dr. Julio Liberani lo califica de estadista y maestro que no fue legislador, sino que legisló con su prédica desde afuera. ${ }^{27}$ Ello se debe a que, pese haber sido un referente nacional, no ocupó posiciones públicas, Molina rechazó ser diputado nacional electo por la provincia de Córdoba para el periodo de 1912-1916. Por lo que, “En 1913 se retiró virtualmente de la política, aunque conservando siempre los mismos ideales. Se entregó en seguida a la vida agrícola, fundando la colonia

del Interior en 1877. En 1898 fue elegido gobernador de la provincia de Buenos Aires. Fue dos veces candidato a presidente de la Nación, en 1886 y en 1892. Pedro Goyena fue un jurisconsulto, escritor y político argentino. Tuvo un papel destacado en la historia argentina por su firme oposición al laicismo que caracterizó a la llamada Generación del 80. Wenceslao Escalante formó parte de esa generación. En 1887 fue diputado en la provincia de Buenos Aires. Es recordado por su paso como Ministro de Agricultura de la Nación (1901-1904). A su inspiración, surge la "Ley de Tierras", que encauzaba la inmigración con finalidades productivas y la fundación del Instituto Superior de Agronomía y Veterinaria, incorporado luego a la Universidad de Buenos Aires como Facultad. Vicente C. Gallo fue elegido diputado nacional en 1912 y senador nacional en 1919 por la Ciudad de Buenos Aires. También ocupó el ministerio del Interior de la Nación durante la presidencia de Marcelo T. de Alvear. Para ampliar, se recomienda consultar "Vicente C. Gallo. Una aproximación a su vida pública. 1890-1942" de Elena Piñeiro. Juan M. Albarenque fue un amigo y compañero de lucha de Pedro C., como lo describe Mansilla (1982, p. 136). También fue presidente de la Convención provincial en 1908. (Frávega, 2000, pp. 67-68).

${ }^{26}$ Juan M. Garro como presidente y Pedro C. como vicepresidente del comité directivo, ambos como representantes de la unión cívica de Córdoba reconocen y apoyan los sucesos en Buenos Aires conducidos por Leandro Alem en 1890 (Frávega, 2000, p. 22).

${ }^{27}$ Discurso de Julio Liberani en Diario La Razón, 2 de junio de 1920.

Anuario de la Escuela de Historia Virtual - Año 10 - N 16 - 2019: pp. 7-24. ISSN: 1853-7049 
Almafuerte, en la que ha permanecido hasta ahora [1920]", ${ }^{28}$ ya retirado de la "acción política y en pleno vigor material" (Mansilla, 1982, p. 148).

\section{Consideraciones finales}

En el contexto de modernización de Argentina a fines del siglo XIX e inicios del siglo XX, la elite fue reinventándose para adaptarse a los cambios que ese proceso estaba ocasionando. Este grupo se consolidó como una elite rural con identidad empresarial modernizadora, donde se destacaron los empresarios agrícolas. Un ejemplo de ello fue Don Pedro Carlos Molina, un sujeto que provenía de una familia de estancieros vinculados a la posesión de una merced de tierras en la época colonial, situada en la zona del actual departamento de Tercero Arriba. Como familia descendiente de españoles conquistadores y dueños de tierras, contaba con prestigio social, tras haber sido varios de sus miembros ocupantes de cargos importantes en el seno de la administración colonial.

Sin embargo, con la desaparición del virreinato y del dominio español, más la reorientación comercial hacia el Atlántico y el avance sobre la frontera, la región de El Salto fue perdiendo su posicionamiento estratégico y, con ello, la familia Molina entró en una fase de declinación en cuanto a la reputación y fue necesario reposicionarse socialmente dentro de la elite cordobesa. En ese marco de modernización, se volvió importante el papel de la educación para la elite rural, de forma más clara en el marco de una región como El Salto que comenzaba a tener menos significatividad en el nuevo entramado económico.

Reconstruir la trayectoria de vida de Pedro C. permitió, por un lado, definir que Molina fue el primer egresado doctor en derecho y ciencias sociales de su familia, en un contexto histórico y estratégico de la región y en un marco social dentro de la elite cordobesa, particular. A la vez, el análisis de este período de su vida permitió observar la incidencia de su formación como abogado y su interés por la economía manifiestas en sus estrategias y prácticas empresariales para conservar e incrementar su patrimonio como empresario rural. Asimismo, se ha observado su repercusión en el plano político, que lo llevó a alcanzar un reconocimiento a nivel nacional dentro de la UCR. En cuanto al primer punto, las diversas estrategias y prácticas empresariales implementadas por Molina a la hora de incrementar su patrimonio personal involucraron: definir sus propiedades mediante deslindes y alambrados, construir canales de riego para sus campos de alfalfa y la cría de hacienda, diversificar su producción añadiendo viñedos, hasta la adquisición de nuevas estancias. Mientras que, su educación e interés político le abrieron las puertas para entablar vínculos económicos y sociales dentro de la elite local y nacional. Por lo que, un aporte significativo en cuanto a estos contactos lo debió tanto a las

${ }^{28}$ El 2 de junio fallece Pedro Carlos Molina. Diario La Razón, 2 de junio de 1920.

Anuario de la Escuela de Historia Virtual - Año 10 - N 16 - 2019: pp. 7-24. ISSN: 1853-7049 
22 | La elite rural y su inversión en la educación formal a fines del siglo XIX...

relaciones construidas por el ejercicio de su profesión como a las derivadas de su actividad política, que en su mayoría se desarrollaron dentro del círculo de sociabilidad: los comités y clubes de la UCR.

\section{Referencias bibliográficas}

Arcondo, A. (1970). Población y Mano de Obra Agrícola - Córdoba 1880-1914. Revista de Economía y Estadística, Tercera Época, 14 (1/4), 7-36.

Bragoni, B. (2001). Asuntos de familia: matrimonio, prácticas sucesorias y protección del matrimonio durante el siglo XIX. Anuario IEHS, 16, 337-364.

Bragoni, B. (2004). ¿Gobiernos de familia? Élites, poder y política en la experiencia argentina del siglo XIX: registro de un ejercicio (pp. 145-177). En B. Bragoni (Comp.). Microanálisis: ensayos de historiografía argentina. Buenos Aires: Prometeo Libros.

Brouwer de Koning, G., Dallaglio, L. y Errasti, V. (2004). Respuesta ciudadana a la propuesta inclusiva de la Unión Cívica de Córdoba. Studia Politicæ, 3, 111-133.

Carbonari, M. R. y Baggini, I. (2004). Población y familias en la región del Río Cuarto. Fines del siglo XVIII. Río Cuarto: Junta de Historia de la Municipalidad de Río Cuarto.

Carbonari, M. R. (2007). Familias y conformación de la elite en época de transición: el caso de un villorio fronterizo, la Villa de la Concepción del Río Cuarto, en el último cuarto del siglo XIX. En VII Congreso Argentino Chileno de estudios históricos e integración Cultural. Salta: Universidad Nacional de Salta.

Carini, G. (2018). Agro, negocio y nueva institucionalidad en las pampas: itinerarios y propuestas de abordaje para el análisis de la representación de intereses agrarios(pp. 417-439). En G. Banzato; G. Blanco y J. Perren (Eds.). Expansión de la frontera productiva, Siglos XIX-XXI. Buenos Aires: Prometeo.

Frávega, O. (2006). Historia de la UCR de Córdoba 1890-2000. Córdoba: Editorial Brujas.

Fernández Seffino, P. (2017). La bandera de la "intransigencia" de la UCR, en la óptica de Pedro C. Molina. Córdoba de fines del siglo XIX y principios del XX. Villa María: Universidad Nacional de Villa María.

Ferrari, M. (2008). Los políticos en la república radical. Prácticas políticas y construcción de poder. Buenos Aires: Siglo XXI.

Ginzburg, C. (2018). Mitos, emblemas, indicios. Morfología e historia. Barcelona: Gedisa.

Hora, R. (2012). Los Anchorena: patrones de inversión, fortuna y negocios (1760-1950). Revista América Latina Historia Económica, 19 (1), 39-66.

Hora, R. (2014). La elite económica Argentina, 1810-1914. Revista de Sociología e Política, 22 (52), 27-46.

Hora, R. (2015). Patrones de inversión y negocios en Buenos Aires en la primera mitad del siglo XIX: la trayectoria de Tomás Manuel de Anchorena. Revista de Historia económica e historia de empresas, VIII (1), 41-82.

Hora, R. (2015). Los terratenientes de la pampa argentina. Buenos Aires: Siglo XXI Editores.

Longa, F. (2010). Trayectorias e historias de vida: perspectivas metodológicas para el estudio de las biografías militantes. Ponencia presentada en VI Jornadas de Sociología. Universidad Nacional de La Plata: La Plata.

López, D. N. (2017). De la política a los negocios: Pedro C. Molina, un empresario inmobiliario (1880-1914). Revista Estudios del ISHiR, 18, 152-169. 
López, M. V. (2009). Elite letrada y alta cultura en el fin de siglo. El Ateneo de Córdoba, 18941913. (Trabajo Final de Licenciatura). Universidad Nacional de Córdoba: Córdoba.

Losada, L. (2006). Sociabilidad, distinción y alta sociedad en Buenos Aires: Los clubes sociales de la elite porteña (1880-1930). Revista Desarrollo Económico, 45 (180), 547-572.

Losada, L. (2012). La educación en la clase alta argentina. Vida doméstica e instituciones (1880-1920). En V. Gessaghi y S. Ziegler (Comps.). La formación de las elites. Investigaciones y debates en Argentina, Brasil y Francia (pp. 27-44). Buenos Aires: Manantial.

Losada, L. (2015). La elite social argentina: visión en perspectiva sobre sus orígenes y formación, 1770-1910. Ponencia presentada en II Reunión Internacional sobre formación de las elites, familia, sociabilidad y procesos de distinción en el acceso a posiciones de elite. FLACSO: CABA.

Mansilla, A. (1982). Historia de Almafuerte. 70ํAniversarios (1912-1982). Almafuerte: Municipalidad de Almafuerte.

Mollis, M. (2016). Universidades nacionales y transnacionales. Siglos XIX al XXI. Rosario: CLACSO. Rosario: Homo Sapiens.

Newton, J. (1972). Diccionario biográfico del campo argentino. Buenos Aires: Artes gráficas Bartolomé U. Chiesino S.A.

Nicola Dapelo, L. (2015). Resumen de tesis: “Estrategias de adaptación a la 'Argentina Moderna' desde el sur de Córdoba: Manuel A. Espinosa (1852-1904)”. Anuario de la Escuela de Historia Virtual, 6 (7), 113-118.

Palermo, A. I. (2006). El acceso de las mujeres a los estudios universitarios (siglo XIX). Revista Argentina de Sociología, 4 (7), 377-417.

Paz Trueba, Y. (2008). Las mujeres en el espacio público a fines del siglo XIX y principios del XX: Un camino alternativo para garantizar el orden. Revista historiapolitica.com. URL: http://historiapolitica.com/datos/biblioteca/paztrueba.pdf. (Consulta 20/03/2019).

Paz Trueba, Y. (2009). La participación de las mujeres en la construcción del Estado social en la Argentina: El centro y sur bonaerenses a fines del siglo XIX y principios del XX. Anuario del Centro de Estudios Históricos "Prof. Carlos S. A. Segreti", 9, 117-134.

Persello, A. V. (2011). Historia del Radicalismo. Buenos Aires: Edhasa.

Puiggrós, A. (1996). ¿Qué pasó en la Educación Argentina? Breve Historia desde la Conquista hasta el Presente. Buenos Aires: Galerna.

Quinteros, V. E. (2017). Mujeres, beneficencia y religiosidad. Un estudio de caso. Salta, segunda mitad del siglo XIX (1864-1895). Revista Andes, 1 (28). URL: http://www.scielo. org.ar/pdf/andes/v28n1/v28n1a02.pdf. Consultado 23/02/2018.

Reguera, A. (2006). Patrón de estancias. Ramón Santamarina: una biografía de fortuna y poder en la pampa. Buenos Aires: EUDEBA.

Sábato, J. (1991). La clase dominante en la Argentina Moderna. Buenos Aires: Imago Mundi.

Sepúlveda Valenzuela, L. (2010). Las trayectorias de vida y el análisis de curso de vida como fuentes de conocimiento y orientación de políticas sociales. Perspectivas Revista de Ciencias Sociales, 21, 27-53.

Sesto, C. (2005). Historia del capitalismo Agrario Pampeano. Buenos Aires: Siglo XXI Editores.

Tognetti, L. A. (2014). Los títulos coloniales y la propiedad plena en la región pampeana cordobesa a fines del siglo XIX. Mundo Agrario, 15 (30), 1-22.

Vidal, G. (2014). Reseña biográfica de dirigentes que interpelaron el mundo del trabajo en Córdoba 1900-1950. Córdoba: Universidad Nacional de Córdoba. 
24 | La elite rural y su inversión en la educación formal a fines del siglo XIX...

Para citar este artículo:

López, Dahyana Nahir (2019). La elite rural y su inversión en la educación formal a fines del siglo XIX: El caso de Pedro C. Molina (1880-1914). Anuario de la Escuela de Historia Virtual, 16, 7-24. 